\title{
Multifactorial expression of IL-6 with update on COVID-19 and the therapeutic strategies of its blockade (Review)
}

\author{
ELENA NICULET $^{1 *}$, VALENTIN CHIONCEL ${ }^{2,3}$, ALINA M. ELISEI ${ }^{4,5}$, MAGDALENA MIULESCU $^{1}$, \\ OLIMPIA D. BUZIA ${ }^{4,5}$, LAWRENCE C. NWABUDIKE ${ }^{6}$, MIHAELA CRAESCU $^{1}$, MIRUNA DRAGANESCU $^{7 *}$, \\ FLORIN BUJOREANU $^{8 *}$, ELISABETA MARINESCU ${ }^{4}$, MANUELA ARBUNE ${ }^{9}$, DIANA SABINA RADASCHIN ${ }^{5}$, \\ CARMEN BOBEICA $^{10}$, AUREL NECHITA ${ }^{1,11}$ and ALIN L. TATU ${ }^{5,7,8}$
}

\footnotetext{
${ }^{1}$ Department of Morphological and Functional Sciences, Faculty of Medicine and Pharmacy, 'Dunărea de Jos' University, 800010 Galati; ${ }^{2}$ Cardio-Thoracic Department, 'Carol Davila' University of Medicine and Pharmacy, 020021 Bucharest;

${ }^{3}$ Clinical Cardiology Department, ‘Bagdasar Arseni’ Emergency Hospital, 041915 Bucharest;

${ }^{4}$ Department of Pharmaceutical Sciences, Faculty of Medicine and Pharmacy, 'Dunărea de Jos' University;

${ }^{5}$ Research Center in The Field of Medical and Pharmaceutical Sciences, ReFORM-UDJ, 'Dunărea de Jos' University, 800010 Galati; ${ }^{6}$ Department of Diabetic Foot Care, 'Prof. N. Paulescu' National Institute of Diabetes, 011233 Bucharest;

${ }^{7}$ Clinical Department, Faculty of Medicine and Pharmacy, 'Dunărea de Jos’ University, 800010 Galati;

${ }^{8}$ Department of Dermatology, 'Sf. Cuvioasa Parascheva' Clinical Hospital of Infectious Diseases, 800179 Galati;

${ }^{9}$ Centre of Medical-Pharmaceutical Research, 'Dunărea de Jos' University, 800010 Galati;

${ }^{10}$ Department of Dermato-Venereology, Doctoral School, University of Medicine and Pharmacy 'Gr. T. Popa', 700115 Iași; ${ }^{11}$ Department of Pediatrics, 'Sf. Ioan' Clinical Hospital for Children, 800487 Galati, Romania
}

Received October 21, 2020; Accepted November 20, 2020

DOI: $10.3892 /$ etm.2021.9693

\begin{abstract}
Interleukin 6 (IL-6), a cytokine produced by various cells of the human body (macrophages, lymphocytes, astrocytes, ischemic myocytes, endothelial cells) has both pro-inflammatory and anti-inflammatory properties, being a key component in regulating various physiologic and pathological processes. The structure of this molecule and the receptor system it possesses are important due to the different activities that IL- 6 can exert; through trans-signaling pro-inflammatory activities are mediated, while through classic signaling, IL-6 is responsible for anti-inflammatory and regenerative activities. IL- 6 signaling is involved in coronary artery disease and the global COVID-19 pandemic. This proatherogenic cytokine reaches elevated serum
\end{abstract}

Correspondence to: Dr Mihaela Craescu, Department of Morphological and Functional Sciences, Faculty of Medicine and Pharmacy, 'Dunărea de Jos' University, 35 Al. I. Cuza Street, 800010 Galati, Romania

E-mail:dr.craescumihaela@yahoo.ro

Dr Diana Sabina Radaschin, Research Center in The Field of Medical and Pharmaceutical Sciences, ReFORM-UDJ, 'Dunărea de Jos' University, 35 Al. I. Cuza Street, 800010 Galati, Romania

E-mail: dianaradaschin@yahoo.com

*Contributed equally

Key words: IL-6, interleukin-6, signaling pathway, receptor, inflammation, cardiovascular, arthritis, COVID-19, tocilizumab levels in the cytokine storm generated by SARS-CoV-2, and is also associated with smoking or obesity-classic cardiovascular risk factors which promote inflammatory states. IL-6 levels are proportionally correlated with dyslipidemia, hypertension and glucose dysregulation, and they are associated with poor outcomes in patients with unstable angina or acute myocardial infarction. IL-6 targeting for treatment development (not only) in cardiovascular disease and COVID-19 is still a matter of ongoing research, although tocilizumab has proven to be effective in reducing the proatherogenic effects of IL-6 and is suggested to improve COVID-19 patient survival.

\section{Contents}

1. Introduction

2. Literature review methodology

3. Interleukin-6

4. Interleukin-6 and the cardiovascular system

5. Cardiovascular system and rheumatoid arthritis link

6. Interleukin-6 and the gastrointestinal system

7. Interleukin- 6 and cancer

8. Interleukin-6 and COVID-19

9. Anti-interleukin-6 therapy

10. Conclusions

\section{Introduction}

Interleukin-6 (IL-6) is a cytokine produced by many cells of the body such as macrophages, lymphocytes, neutrophils, 
adipocytes, astrocytes, mesothelial cells as well as cardiovascular components including endothelial cells, vascular smooth muscle cells and ischemic myocytes (1-4). In regards to its many properties and sources, IL- 6 has been known for a long time under various names including interferon- $\beta 2$, B cell stimulatory factor-2, $26 \mathrm{~K}$ factor, hybridoma growth factor, hepatocyte stimulatory factor, cytotoxic $\mathrm{T}$ cell differentiation factor, or plasmacytoma growth factor (5).

IL-6 regulates various physiological processes including hematopoiesis, immune response, acute phase response and the transition from acute to chronic inflammation (6). Despite the fact that IL-6 provides pro-inflammatory and anti-inflammatory properties, it is generally considered a pro-inflammatory cytokine (7), and dysregulation of IL-6 production represents a major contributor to the pathogenesis of chronic inflammatory and autoimmune diseases.

The role of IL-6 in the pathogenesis of many diseases, including rheumatologic, autoimmune, endocrine, cardiovascular or neurological diseases, its advantages and disadvantages and the therapeutic approach designed in order to inhibit the function of this specific inflammatory cytokine (anti-IL-6 therapeutic agents) are major topics of current research such that the number of related studies has increased substantially in the recent literature.

\section{Literature review methodology}

We performed an updated narrative review of studies published between 2000 and 2020 in the current literature which were focused on the cytokine IL- 6 and its functional role, its intervention especially in the pathophysiology of inflammatory, autoimmune and cardiovascular diseases, the correlation between IL- 6 and cardiac risk factors, the beneficial or detrimental cardiovascular outcome of anti-rheumatic therapies after IL-6 receptor blockade and its pathophysiological implications in various organ system diseases, including the novel COVID-19 global crisis.

Databases such as PubMed, Medline, ScienceDirect Freedom Collection, Elsevier were used in the search for related articles, by introducing the terms IL- 6 and anti-IL-6 alone or in combination.

\section{Interleukin-6}

IL-6, a glycoprotein from the IL-6 family, involved both in health and disease, is present physiologically in the serum in picogram per milliliter $(\mathrm{pg} / \mathrm{ml})$ amounts. IL-6 can become elevated in basically any inflammatory state, even during exercise through skeletal muscle release of IL-6 or even after multiple trauma (proportional to the extent of the injury), being able to reach values of micrograms per milliliter $(\mu \mathrm{g} / \mathrm{ml})$ in severe conditions such as septic shock (8-10).

Multifunctional IL-6 is involved in many physiologic activities, disease initiation and progression, being more likely associated with the male gender (11); the pleiotropic quality of this cytokine makes it a key role player in many physiologic processes.

Physiologic processes in which IL-6 is involved are numerous, and include ageing, menses, spermatogenesis, bone strengthening, liver regeneration and skin proliferation (5).
IL-6 is involved in brain development including cognitive processes of memory formation and cognitive flexibility by promoting differentiation and proliferation of neurons $(5,12)$. IL-6 is also involved in hematopoiesis, metabolism (13) and post-prandial glycemia improvement. Through delayed gastric emptying it regulates appetite and is such involved in body weight control, as a result of hypothalamic neuropeptide regulation (14). IL-6 also plays a role in immune modulation/host defense (acute phase reaction, B lymphocyte differentiation, $\mathrm{T}$ helper activation and $\mathrm{T}$ regulatory lymphocyte inhibition). In gut associated lymphoid tissue (GALT), IL-6 is the key factor in balancing Th17 and Treg cells (4,15-17).

Important pathologic processes with IL-6 involvement include inflammatory states. It is one of the earliest cytokines involved in inflammation, inducing acute inflammation, mobilizing neutrophils from the bone marrow and activating eosinophils; as an endogenous pyrogen, it can ensure the transition from an innate to an adaptive immunity, and also immunoglobulin secretion. It is involved in chronic inflammatory diseases including (osteo) arthritis, rheumatoid arthritis, pulmonary fibrosis, asthma, chronic obstructive pulmonary diseases (some with autoimmune background, such as vitiligo, for which piperine treatment seems to lower IL-6 levels) (18-23). IL-6 is also involved in cancer development and progression as is the case for head and neck squamous cell carcinoma, for which cumulative hydrochlorothiazide use seems to be a risk factor. It is frequently involved in liver and breast cancer, head and neck squamous cell carcinoma by exerting pro-angiogenic properties (this factor makes it also a valuable component in wound healing) and development of inflammation-associated cancers. In cancer prevention, IL- 6 directs NK cells at the tumor site during exercise (4,14,15,24-26). Il-6 is involved in skin disorders including rosacea, vitiligo, lichen planus and contact allergy (19-22,27-30). IL-6 directly and indirectly inhibits human herpes virus-1 (HHV-1) infection. It is involved in humoral responses against influenza virus post-vaccination, registers high levels in advanced human immunodeficiency virus (HIV) infection, has antibacterial properties by inhibiting gram-negative bacteria and is involved in fighting parasitic infections such as filaria (31-37). It is involved in nervousness (13), osteoporosis (as a protective agent by promoting osteogenesis through angiogenesis) (4), cognitive dysfunction in neurodegenerative diseases (Huntington's, Parkinson's and Alzheimer's diseases, multiple sclerosis) and psychiatric disorders (major depression, schizophrenia, bipolar disorder) $(12,38)$. IL-6 is involved in metabolic syndrome including obesity and type 2 diabetes $(11,38)$, coagulation disorders (39), neuropathic pain, autoimmune disorders and ischemic injury (18).

Structure and receptor system. The structure of the IL-6 cytokine, of its receptors and receptor-complexes represents information valuable for understanding the basis of this cytokine's multifunction. This single chain glycoprotein has four helix bundles, A-D, which form a ribbon-like arrangement and run in opposite directions (A and B vs. C and D) (5).

The multifunctional activity of IL- 6 is mediated by its cell surface type-I receptor complex consisting of two components-the $\alpha$-receptor subunit (CD126 or IL-6R), a type I transmembrane glycoprotein weighing $80 \mathrm{kDa}$, and the 
signal-transducing $\beta$-receptor subunit (CD130 or gp130), a type I transmembrane protein of $130 \mathrm{kDa}(13)$.

gp130 is an ubiquitous receptor, a signal transducer, commonly found on the surface of all cell types and shared between the IL- 6 family members. IL-6R, on the other hand, is a specific receptor, found on a limited number of cell types including monocytes, macrophages, hepatocytes, B cells and $\mathrm{T}$ cells (few subpopulations) and is made up of a number of three domains-D1, D2, D3. D1, or Ig domain, and forms a link with the cytokine binding domain (CBD), made up of D2 and D3 $(5,33)$.

IL-6R can be found in two forms, soluble (sIL-6R) and membrane-bound (mIL-6R). mIL-6R is found in liver cells, neutrophils, $\mathrm{T}$ cells or monocytes and is involved in physiological activities such as acquired immunity. sIL-6R is the product of proteolytic cleavage of members from the metalloproteinase gene family, ADAM10, ADAM17, or the result of the alternative splicing of IL-6R mRNA; it can also acts as a carrier for IL-6, taking it to the pathologic site which has gp130-the tallest cytokine receptor with an extracellular region with 6 domains (D1 to D6). As for IL-6R, D1 is the Ig domain, D2 and D3 form the CBD and D4, D5 and D6 bind with IL-6, being involved in other signaling mechanisms $(5,33)$.

The signal transduction mechanisms of IL-6 have been thoroughly investigated which include classic signaling, trans-signaling and cluster signaling; all of these rely on the process of mgp130 (membrane-bound gp130) homodimerization which then activates the following downstream signaling pathways: JAK/STAT, ERK and PI3K. By activating these two signaling pathways, ERK/MAPK and JAK/STAT, IL-6 can exhibit distinct, but also contradictory functions, explaining its antagonistic pro-inflammatory and anti-inflammatory activities $(5,33)$.

On target cells which express both receptors, IL-6R and gp130, the first step which IL-6 takes, is to bind to mIL-6R, forming the IL-6/mIL6R complex and thus triggering the creation of a macromolecular complex with two identical proteins, mgp130, the homodimerization process mentioned earlier, part of the classic signaling (40).

The IL-6 trans-signaling is a pro-fibrotic transduction mechanism that uses sIL-6R in order to bind to IL-6 and form an IL-6/sIL6-R complex which detaches itself from the cell surface with the help of two metalloendopeptidases-disintegrin and metalloproteinase 17-ADAM17 $(33,40)$; this complex then activates the cells expressing only gp130. The agonist activity of sIL-6R is thus revealed by amplifying IL-6 signaling in cells that lack IL-6R. Trans-signaling is an inflammation regulator involved in many diseases including rheumatoid arthritis, inflammatory bowel disease, pancreatic cancer, diabetes and pulmonary fibrosis (41).

Cluster signaling, a newly discovered type of signaling model, is a complex process described during the interaction between $\mathrm{T}$ helper17 (Th17) and dendritic cells. The IL-6/mIL-6R complex, found on the transmitter cells, sets off the activation of mgp130 on the receiver cells (13).

The importance of IL-6 signaling stems, on the one hand, from the molecular link that it creates between acute, chronic inflammation and fibrogenesis, IL- 6 being a critical mediator in inflammatory processes by helping inflammatory cell recruitment to the affected area; trans-signaling, more specifically, has been associated with pro-fibrotic processes and tissue remodeling $(40,42)$. This fact is also strengthened by the IL-6 gene polymorphism which has been associated with acute and chronic inflammatory states, and, subsequently with fibrosis (31). On the other hand, IL-6 signaling is important due to the fact that, depending on the biochemical pathway that is involved, it has implications both in physiological and pathological activities (5), trans-signaling mediating pro-inflammatory activities of IL-6 and classic signaling mediating regenerative and anti-inflammatory activities (41).

\section{Interleukin-6 and the cardiovascular system}

IL-6R signaling seems to have a determinant role in the development of coronary artery disease (CAD). Obesity, cigarette smoking, infection or stress are determinants in the development of elevated serum IL-6 concentrations and lead to different inflammatory responses. Increased IL-6 levels are strongly correlated with hypertension, dyslipidemia and glucose dysmetabolism, traditional cardiovascular risk factors which finally promote atherosclerosis, the main cause of cardiovascular disease (CVD) $(43,44)$.

Over the last few decades, the role played by inflammation in the process of atherosclerosis development has been widely researched (45), making identification of detailed pathways which link inflammation with atherosclerosis and CVD, a promising basis for new possible therapeutic targets. In the pathophysiology of CVD, IL-6 plays a causative role, as a marker of inflammation related to cardiovascular risk $(46,47)$ and as a significant proatherogenic cytokine (48).

Other studies have found that plasma C-reactive protein (CRP) levels are strongly linked with atherosclerosis, showing robust results as a marker of systemic inflammation associated with cardiovascular risk (49). Plasma CRP is produced primarily by liver cells in response to inflammatory stimulation exerted by cytokines, such as IL-6. Different research studies have reported IL-6 to be an upstream inflammatory cytokine that is responsible for chronic-inflammation-related atherogenesis (50).

Inflammatory biomarkers are known for their association with many cardiovascular events (51-53). These markers, including IL-6, have a predictive value demonstrated in patients with pre-existing CAD and cerebrovascular disease $(54,55)$. The existing extensive literature aids in supporting the role of chronic inflammation in the development and progression of atherosclerosis (56), as various reports state that elevated levels of these inflammatory agents (IL-6 including) have been linked to acute ischemic conditions and are by far predictors of recurrent events in those with CAD $(51,52,56)$.

There are multiple mechanisms by which circulating IL-6 contributes to the development of CAD including endothelial, coagulant and metabolic mechanisms. Serum IL-6 is a main stimulator of hepatic acute-phase response (associated with increased blood viscosity and increased platelet number and activity). Autocrine and paracrine activation of monocytes by IL-6 in the vessel wall activates the deposition of fibrinogen (CRP and fibrinogen are both strong risk factors for CAD). Circulating IL- 6 also stimulates the hypothalamic-pituitary-adrenal (HPA) axis which is associated with central obesity, hypertension, and insulin resistance $(57,58)$. 
The positive association between IL-6 serum concentration and mortality risk from CAD has been reported by several studies $(51,55,59,60)$. Elevated serum IL-6 levels are linked to an increased risk of CAD patient mortality but the cytokine's direct causal role in death is yet to be confirmed (61). Serum IL-6 levels are a major predictor for short- and long-term death rates, being a possible mortality biomarker in CAD patients.

The first association between IL- 6 and the development of cardiovascular disease was shown thirty years ago in a case of cardiac myxoma (62). Although acute IL-6 response can protect and preserve myocardial tissue, the chronic elevation of IL-6 induces depressed myocyte function (58). Increased levels of IL- 6 have been associated with a detrimental outcome concerning all CVDs (63). IL-6 can cause cardiac hypertrophy through gp130 activity. Continuous and excessive production of IL- 6 promotes myocardial injury, congestive heart failure (1) and a higher risk of future myocardial infarction even in apparently healthy young men not only in older people (64).

A recent report which highlighted IL-6 involvement in CHD development also reported that IL6-R blockade reduced systemic and articular inflammation (47); whether this could decrease the risk of CVD, or not, is yet unknown. Furthermore, this causal association between IL-6R-related pathways and coronary heart disease is also strongly supported by a collaborative randomized analysis (47). As such, targeting IL-6R may be a novel therapeutic approach for the prevention of CHD.

The serum level of IL-6 is also associated with unfavorable clinical outcomes in patients hospitalized for unstable angina and ST-elevated myocardial infarction (STEMI) (47,55). Many chronic conditions (common causes of death in the elderly) may stimulate and maintain a systemic inflammatory state which can be measured by increased levels of serum IL-6 or other pro-inflammatory cytokines (65).

Associations between serum IL-6 and death rates have been researched by many studies in the past, but with important conflicting results. The Women's Health and Aging study revealed that among women with prevalent CVD, those who registered higher plasma levels of IL- 6 had an increased mortality risk (more than 4-fold) as compared to those found in the lowest tertile; this study did not manage to find such an association among female patients without CVD (65). IL-6 has been found to be more strongly associated with an all-cause and cardiovascular death rate than CRP (54).

Other recent studies have shown that elevated levels of serum IL-6 provide valuable information for the risk assessment of long-term cardiovascular mortality in patients with STEMI and are a powerful predictor of cardiovascular and all-cause mortality $(55,66)$.

Plasma IL-6 level has been shown to be good predictors for short-and long-term mortality in patients with acute heart failure (HF); also, two prospective studies have associated serum IL-6 levels with CHD. Increased IL-6 concentrations can be a predictive factor for mortality in elderly patients with HF $(64,67)$; plasma IL-6 is a stronger and more powerful predictor for total and cardiovascular mortality in patients undergoing hemodialysis, even more than CRP (68).

Gender-specific aspects concerning death rates is still a problematic aspect, this including the issue of inflammatory markers (69). It is thus necessary to further study the gender specificity of mortality in relation to the inflammatory hypothesis and CAD.

Acute myocardial ischemia/reperfusion (I/R) has been proven to be associated with an inflammatory response which may contribute to I/R-induced injury of the heart. Upon cardiac I/R, one of the major inflammatory mediators that are quickly released is IL-6. Chronically elevated IL-6 levels is a factor associated independently with acute coronary syndromes, thus suggesting an etiologic involvement of this cytokine in myocardial injury (70-72). IL-6 is a contributing factor in the adverse remodeling which takes place at 35 days following I/R (73).

On the other hand, the NOMAS/Northern Manhattan Study has assessed the relationships between high-sensitivity CRP (hsCRP)/IL-6 and stroke. The stroke risk associated with the inflammatory biomarkers (hsCRP and IL-6) depended on the relationship to one another. When hsCRP-quartile dominated the IL- 6 quartile, risk was increased, and when IL- 6 was over hsCRP, the risk was decreased. Having combined panels of inflammatory biomarkers might help in predicting ischemic events; this is also valid even when their individual measurements are not capable of doing so (74). IL-6 contributes to the determination of the severity of ischemic stroke and that it affects clinical outcomes in this pathology (74); thus being said, more studies are needed in order to evaluate this risk classification and to assess the importance of inflammatory markers in stroke evolution.

Treatments that lower systemic inflammatory markers such as IL-6 show beneficial effect on atherosclerosis and, respectively, on its complications. The blockade of IL- 6 by neutralizing IL-6R with monoclonal antibody tocilizumab (an interleukin-6 receptor antagonist) reduces systemic and articular inflammation (75-77).

\section{Cardiovascular system and rheumatoid arthritis link}

In several clinical human trials, elevations in serum lipid levels were found among those receiving tocilizumab (TCZ). This treatment, although it develops significant dyslipidemia and increases body weight, also significantly reduced IL-6 activity and provided dramatic improvement in endothelial function in a high risk rheumatoid arthritis (RA) population (78-80).

In a head-to-head randomized controlled trial (RCT) of TCZ monotherapy vs. adalimumab monotherapy that enrolled 325 patients with RA, TCZ proved to be superior to adalimumab in attenuating signs and symptoms of RA; more patients in the TCZ group had increases of 17 to $25 \%$ in total cholesterol, low-and high-density cholesterol, and triglyceride levels, more than those in the adalimumab group. Nonetheless, although increases in lipid levels with TCZ treatment compared with treatment with other biologic agent were registered, an excess risk for cardiovascular events, stroke, heart failure hospitalization, or cardiac death has not been yet determined $(80,81)$.

Patients with RA have an increased risk of sudden cardiac death, a fact which is not entirely explained by RA disease characteristics. Corrected QT (QTc) interval prolongation is a marker more frequently found in patients suffering from RA, than in those without RA. TCZ treatment in patients with RA decreases the QTc interval by reducing systemic inflammation. 
Furthermore, given the anti-arrhythmic potential of TCZ treatment, it may have beneficial effects in those RA patients (82).

$\mathrm{RA}$ is associated with an increased risk of congestive heart failure possibly through inflammatory mechanisms. Studies have tested the hypothesis that the powerful anti-inflammatory effect of anti-IL-6 TCZ therapy might lead to a reduction in left ventricular dysfunction in patients with RA. It demonstrated that the improvement in left ventricular regional function by TCZ treatment may correlate with reduction in RA disease activity (83).

\section{Interleukin-6 and the gastrointestinal system}

The cytokine IL- 6 , part of the inflammatory cascade and an indicator of systemic injury, is involved in immunologic signaling, in reticulo-endothelial system activity, the acute phase response in the liver and is part of the liver's regenerative process. After partial liver resection, IL-6 serum levels were found to increase as early as 30 min post-resection and were maintained at an increased level for several days afterward $(84,85)$. The effects of IL- 6 on the liver have also been linked to the muscle-liver axis-which is involved in metabolism homeostasis, with protection against non-alcoholic fatty liver disease through the activation of the autophagy-lysosomal liver pathway and evasion of liver steatosis (86).

IL-6 is a potent vascular relaxer and it is involved in sepsis at the intestinal level through the dilatation of the constricted vasculature; it allows proper oxygenation and inhibits the processes of necrosis and apoptosis of intestinal epithelial cells which are induced through hypoxia. In the intestines, IL-6 has also proven to have antibacterial effects, lowering the load of pathogenic Campylobacter even before $\operatorname{IgA}$ is involved, thus implying the involvement of a non-immune mechanism (87). As a critical factor for the survival and differentiation of T cells, IL-6 is a key player in irritable bowel disease (a T cell-mediated immune disorder) and by participating in chronic inflammation it continuously stimulates the production of growth factors and cytokines which in turn allow the growth and survival of malignant cells. In consequence, besides it being involved in colitis, both Crohn's disease and ulcerative colitis, IL-6 is also linked to the development of colorectal cancer $(88,89)$.

This cytokine is also produced by hematopoietic and epithelial neoplastic cells, as in pancreatic carcinoma, and it modulates the behavior of these cells by interacting with vascular endothelial cells and acting as a regulator for vascular permeability. The increased values in obesity have been in direct link with type 2 diabetes; a paradoxical observation was made which stated that through stimulation of glucagon-like peptide-1 (GLP-1) in the pancreas by IL-6 administration insulin secretion was stimulated, improving plasma glucose levels $(90,91)$.

IL-6 is also involved in gastro-duodenal diseases, the gastric mucosal levels of this cytokine being increased in Helicobacter pylori-associated chronic gastritis and also in individuals with gastric cancer which are positive for this bacteria (another chronic inflammation-cancer development cascade with which IL-6 is linked) (92). High levels of IL-6 have been proven to be involved in delayed gastric emptying, with lower postprandial glucose levels in normal and type-2 diabetes individuals (93).

\section{Interleukin-6 and cancer}

IL-6 is involved in pancreatic cancer which is supported by immunohistochemistry studies which revealed overexpression in the tissues examined. Here, the tumor cells act as secretory cells for this cytokine. IL-6 is a key player in cancer progression by supporting the proliferation and ensuring the survival of neoplastic cells through the JAK/STATs pathways; this plays a further role in metastatic progression, establishing the poor prognosis of pancreatic cancer, but also that of breast cancer (94).

Tumor-derived IL-6 is multifaceted through the many activities in which it is involved, acting not only on the tumor itself, but also on the immune system. Thus, it acts as a growth factor in breast and prostate cancers, as a differentiation-inducer for neoplastic cells in lung adenocarcinoma (95). It promotes angiogenesis and tumor invasion (important factors in local and systemic tumor extension and metastasis), having an important role in hepatocellular carcinoma and Wilms tumor. IL-6 is also involved in colon cancer where it facilitates tumor immune escape by regulating tumor resistance to cytotoxic cells (determining decreased cell death receptor expression) and it drives and maintains pro-tumorigenic inflammatory loops. High levels of serum IL-6 (and the associated worse prognosis) have been found in patients with metastatic renal cell carcinoma, lung, breast and prostate cancers, Hodgkin's disease, multiple myeloma or ovarian carcinoma. However, cancer-bearing animal-based studies have shown that exogenous administration of IL-6 has antitumor properties, in direct contrast with the pro-tumorigenic activities described (96-99).

As in the pro-inflammatory-anti-inflammatory dichotomy described earlier in this article, the former antagonistic activities might be linked to the different signaling pathways that IL-6 and its receptor system use.

\section{Interleukin-6 and COVID-19}

The most recent global pandemic of the 21st century, which originated in the city of Wuhan, Hubei Province, China, was caused by the highly contagious novel beta-coronavirus-SARS-CoV-2 (the third lethal human coronavirus), the etiologic agent of a pneumonia causing severe respiratory acute syndrome $(100,101)$. Almost $19 \%$ of cases are severe or in a critical state (100).

The World Health Organization (WHO) named this deadly outbreak COVID-19, an acronym for COronaVIrus Disease from 2019, spreading extremely fast between continents and having severe consequences on everyday life $(100,101)$. On April 21, 2020, the WHO revealed in its 92nd Situation report a total number of more than 2,300,000 people infected, with over 160,000 deaths worldwide (102).

The pathogenesis of COVID-19 is the subject of current research and until now a dysregulated immune response, the cytokine storm, seems to be one of the main culprits. The cytokine storm, or the cytokine release syndrome (CRS), is a systemic inflammatory response to various factors (SARS-CoV-2), signifying the overwhelming and uncontrolled release of high levels of pro-inflammatory cytokines, a specific finding in the critically ill patients infected with the novel virus. The importance of this overly active immune system 
response stems from the fact that those with high cytokine concentrations have a severe and rapid progression towards cardiovascular collapse, multiple organ dysfunction syndrome (MODS) (including renal and liver failure) and, finally, exitus. The specificity of the organs affected resides in the fact that this virus binds to the angiotensin-converting enzyme 2 (ACE2) receptor which is particularly massively expressed on the cell surfaces of the lung, kidney and heart (103-105).

Recent Chinese clinical experiences incriminate IL-6 as one of the main cytokines involved in such coronavirus-induced storms, being produced mainly by activated macrophages. One study even reports severe cases as having lymphopenia-diminished numbers of $\mathrm{CD}^{+}$and $\mathrm{CD} 8^{+}$ lymphocytes (with a more accentuated decrease in CD8 ${ }^{+}$cells), accompanied by increasing levels of inflammatory cytokines and chemokines in the peripheral blood including IL-6, IL-1 $\beta$, IL-2, IL-10, IFN- $\delta$, IP10 (induced protein 10) and MCP-1 (monocyte chemoattractant protein-1) (103-105).

A cohort study found that IL-6 blood levels correlated with mortality in patients suffering from severe forms of COVID-19, being an important biomarker for predicting disease severity and prognosis (along with IL-2R which seems to have the same predictive value) (105). In this complex pathogenic mechanism, IL-6 plays an essential role in generating T helper cells (more specifically Th17 lymphocytes which seem to be overly activated) in the process of interaction between $\mathrm{T}$ cells and dendritic cells. IL-6 levels were reported to vary between the severely affected patients (having highly elevated levels), who were admitted in the Intensive Care Unit (ICU)-ICU patients and those who had milder disease manifestations (non-ICU patients). This is important for the therapeutic decision: whether IL-6 blockade is effective in all patients or only in those suffering from CRS, and for the ability of classifying patients according to disease severity, thus being useful in establishing risk stratification and evaluating patient prognosis (105).

As such, IL-6 being the key molecule in CRS, it is of utmost urgency and importance to find a suitable treatment that will ensure patient survival, especially in the case of those critically ill patients. Until now, therapeutic agents are scarce, patients having limited options for treatment.

\section{Anti-interleukin-6 therapy}

Anti-IL-6 therapeutic agents are a class of biologic immune modulators which includes antibodies directed against the IL-6 receptor/ligand (tocilizumab, sarilumab) and also inhibitors of IL-6 signal transduction (JAK inhibitors such as baricitinib, tofacitinib), making them useful in many chronic inflammatory conditions. Targeting IL-6 pathways is a more global approach, which includes targeting two of the three pathways; classic signaling and trans-signaling (more specifically sIL-6R and mIL-6R); this is not a novel approach, but an attractive one nonetheless due to the many activities exerted by this cytokine.

Tocilizumab (TCZ). TCZ is a humanized monoclonal antibody (mAb) directed against the IL-6 receptor (IL-6R), more specifically against its $\alpha$ subunit and is approved for use in diseases such as systemic juvenile idiopathic arthritis and RA, having seemingly positive effects in Crohn's disease and Castleman disease $(79,104,106)$.
A phase III study involving 623 patients (79) revealed that this therapeutic agent has significantly improved the clinical and laboratory signs in RA patients-the OPTION study. TCZ administered as $8 \mathrm{mg} / \mathrm{kg} / \mathrm{dose}$ (alone or in combination with methotrexate) registered a significant decrease in CRP levels, even as low as their normal range. Improvement concerning the hemoglobin levels (which are low in those suffering from a chronic inflammatory disease, with the characteristic secondary anemia) was also shown. Another positive effect of TCZ, administered at the same dosage, was revealed by the LITHE study where the radiographic findings in those with RA were significantly improved (106). All of these studies, including ACT-RAY, FUNCTION and SURPRISE have shown a more beneficial outcome in those following combination therapy, rather than monotherapy. Other positive effects of such treatment were registered in the physical and mental scores of RA patients $(79,106,107)$.

In what concerns the new COVID-19 pandemic, IL-6R blockade seems to be a key treatment option for the critically ill patients who suffer from CRS (IL-6 being a key cytokine). CRS inhibition could be possible through the use of TCZ because it binds to both forms of IL-6R (membrane-bound and soluble) and because it also inhibits the signal transduction that these two receptors mediate (100). It is suggested that a combination between immune modulation agents and antiviral agents might be more beneficial for patient survival. The results reported major improvements in elevating the peripheral blood lymphocyte numbers and in reducing the patient's fever and lung opacities, all the while reducing the IL-6 blood levels which had an initial spike increase followed by constant decrease.

In 2017, TCZ was approved by the Food and Drug Administration (FDA) for the treatment of CRS in the case of a pediatric female patient suffering from acute lymphoblastic leukemia (ALL) treated with chimeric antigen receptor T-cell immunotherapy (CAR-T therapy). The CRS caused by CAR-T therapy was successfully treated with TCZ, improving the patient's overall health status and without affecting the ALL therapy $(100,103,104)$.

As any other therapeutic agent, TCZ has the capacity of causing adverse effects such as: Infections, hypertension, dermatitis, rashes, dyspepsia, abdominal pain, oral and peptic ulcers, headaches, increases in lipid levels (hypercholesterolemia) and liver function tests such as aminotransferases, and leucopenia $(79,106,107)$. Some trials even reported TCZ to be a CVD risk factor, as patients who underwent treatment with this agent were much more likely to suffer from major cardiovascular events (104).

Sarilumab. Another human mAb targeting IL-6R $\alpha$, sarilumab (SAR153191/REGN88), binds with high affinity sIL-6R $\alpha$ and mIL-6R $\alpha$, without any cell-mediated toxicity.

It showed promising results in studies which enrolled patients suffering from moderate to severe RA-such as MOBILITY, MONARCH and TARGET, where it lowered CRP levels and stopped joint damage progression in a dose-dependent manner, as monotherapy or combined therapy $(41,106)$.

The adverse effects ranged from infections, hypersensitivity reactions (no anaphylaxis) to laboratory abnormalities including hypercholesterolemia, increased liver function tests, leucopenia and thrombocytopenia $(41,106,108)$. 
Olokizumab and sirukumab. As a humanized anti-IL-6 $\mathrm{mAb}$, olokizumab has proven to be as effective as and with similar side effects as TCZ in various clinical trials. This anti-IL- 6 agent has the property of blocking the final assembly of this cytokine's signaling complex. Olokizumab registered a very low increase in triglyceride blood levels, without any increases in the total cholesterol levels or its low density and high density subunits, as opposed to TCZ findings. Sirukumab, a human $\mathrm{mAb}$, reported similar side effects in human trials as with TCZ (especially regarding laboratory abnormalities), but without the presence of opportunistic infections. The safety and efficacy profiles of TCZ, sarilumab, olokizumab and sirukumab have proven to be similar in reported studies $(109,110)$.

Besides the treatment possibilities listed, what could be of use concerning the COVID-19 pandemic are adequately implemented preventive measures, such as: early detection of those infected, implementation of national procedures for the detection and management of the virus, the continuous up-dating of the latest scientific discoveries concerning this disease with international collaboration and assistance (111); having these in mind, the most important step in disease prevention remains the development of a vaccine, although it has been a difficult task to manage due to the many unknowns concerning SARS-CoV-2 (112).

\section{Conclusions}

Long term elevated levels of IL-6 have now been proven to be associated with cardiovascular risk and to be involved in the pathogenesis of cardiovascular diseases, a causality link being established between this cytokine IL- 6 and CHD; thus being said, an etiological link between serum IL-6 levels and mortality in patients with arterial heart disease yet remains to be proven. Targeting IL-6R in order to decrease cardiovascular risk needs further studies for confirmation, as clinical research has proven monoclonal antibodies to have an increasing effect on serum lipid levels, a well-known factor for CHD development and progression.

More studies are indeed needed in order to evaluate the entirety of the positive and adverse effects of tocilizumab, sarilumab, olokizumab and sirukumab in the field of cardiovascular diseases, although in the case of tocilizumab it appeared to significantly reduce the proatherogenic effect of IL-6. Concerning the novel COVID-19 global crisis and the CRS this virus generates, it is necessary to better understand the pathogenesis of this viral disease in order to find suitable immune therapies.

\section{Acknowledgements}

Not applicable.

\section{Funding}

No funding was received.

\section{Availability of data and materials}

All information is documented by relevant references.

\section{Authors' contributions}

ALT, VC, ODB, MD, MM and CB contributed to the acquisition, analysis and interpretation of data. MC, FB, DSR and EN made substantial contributions to the conception and design of the work, while EM, AME, MA, LCN and AN supervised and substantially revised this work. All authors read and approved the final manuscript.

\section{Ethics approval and consent to participate}

Not applicable.

\section{Patient consent for publication}

Not applicable.

\section{Competing interests}

The authors declare that they have no competing interests.

\section{References}

1. Coughlin BA, Trombley BT and Mohr S: Interleukin-6 (IL-6) mediates protection against glucose toxicity in human Müller cells via activation of VEGF-A signaling. Biochem Biophys Res Commun 517: 227-232, 2019.

2. Matthes AT, Manfroi B and Huard B: Revisiting IL-6 antagonism in multiple myeloma. Crit Rev Oncol Hematol 105: 1-4, 2016.

3. Rizzo MD, Crawford RB, Bach A, Sermet S, Amalfitano A and Kaminski NE: Imiquimod and interferon-alpha augment monocyte-mediated astrocyte secretion of MCP-1, IL-6 and IP-10 in a human co-culture system. J Neuroimmunol 333: $576969,2019$.

4. Niu X, Chen Y, Qi L, Liang G, Wang Y, Zhang L, Qu Y and Wang W: Hypoxia regulates angeogenic-osteogenic coupling process via up-regulating IL- 6 and IL-8 in human osteoblastic cells through hypoxia-inducible factor- $1 \alpha$ pathway. Cytokine 113: 117-127, 2019.

5. Kaur S, Bansal Y, Kumar R and Bansal G: A panoramic review of IL-6: Structure, pathophysiological roles and inhibitors. Bioorg Med Chem 28: 115327, 2020.

6. Choy E and Rose-John S: Interleukin-6 as a multifunctional regulator: Inflammation, immune response, and fibrosis. J Scleroderma Relat Disord 2 (Suppl 2): S1-S5, 2017.

7. Scheller J, Chalaris A, Schmidt-Arras D and Rose-John S: The pro- and anti-inflammatory properties of the cytokine interleukin-6. Biochim Biophys Acta 1813: 878-888, 2011.

8. Prenissl N, Lokau J, Rose-John S, Haybaeck J and Garbers C: Therapeutic blockade of the interleukin-6 receptor (IL-6R) allows sIL-6R generation by proteolytic cleavage. Cytokine 114: $1-5,2019$.

9. Liang AP, Drazick AT, Gao H and Li Y: Skeletal muscle secretion of IL-6 is muscle type specific: Ex vivo evidence. Biochem Biophys Res Commun 505: 146-150, 2018.

10. Karthick SR, Sen RK, Gopinathan NR, Dhillon MS, Nada R and Sharma RR: Can IL-6 predict the development of fat embolism in polytrauma? A rabbit model pilot experimental study. J Clin Orthop Trauma 11 (Suppl 1): S86-S92, 2020.

11. Del Giudice M and Gangestad SW: Rethinking IL-6 and CRP: Why they are more than inflammatory biomarkers, and why it matters. Brain Behav Immun 70: 61-75, 2018.

12. Bialuk I, Taranta A and Winnicka MM: IL-6 deficiency alters spatial memory in 4- and 24-month-old mice. Neurobiol Learn Mem 155: 21-29, 2018.

13. Zhou E, Yan F, Li B, Chen M, Tu X, Wu S, Wu H, Wei X, Fu S, Wu L, et al: Molecular and functional characterization of IL-6 receptor (IL-6R) and glycoprotein 130 (gp130) in Nile tilapia (Oreochromis niloticus). Dev Comp Immunol 106: 103629, 2020.

14. Ellingsgaard H, Hojman P and Pedersen BK: Exercise and health-emerging roles of IL-6. Curr Opin Physiol 10: 49-54, 2019. 
15. Unver $\mathrm{N}$ and McAllister F: IL-6 family cytokines: Key inflammatory mediators as biomarkers and potential therapeutic targets. Cytokine Growth Factor Rev 41: 10-17, 2018.

16. Dittel LJ, Dittel BN and Brod SA: Ingested ACTH blocks Th17 production by inhibiting GALT IL-6. J Neurol Sci 409: 116602, 2020.

17. Gao S, Hu J, Wu X and Liang Z: PMA treated THP-1-derived-IL-6 promotes EMT of SW48 through STAT3/ERK-dependent activation of $\mathrm{Wnt} / \beta$-catenin signaling pathway. Biomed Pharmacother 108: 618-624, 2018.

18. Santhosh Kumar S, Sajeli Begum A, Hira K, Niazi S, Prashantha Kumar BR, Araya $\mathrm{H}$ and Fujimoto Y: Structure-based design and synthesis of new 4-methylcoumarin-based lignans as pro-inflammatory cytokines (TNF- $\alpha$, IL- 6 and IL-1 $\beta$ ) inhibitors. Bioorg Chem 89: 102991, 2019.

19. Tatu AL, Clatici VG and Nwabudike LC: Rosacea-like demodicosis (but not primary demodicosis) and papulopustular rosacea may be two phenotypes of the same disease-a microbioma, therapeutic and diagnostic tools perspective. J Eur Acad Dermatol Venereol 33: e46-e47, 2019

20. Tatu AL, Ionescu MA and Nwabudike LC: Contact allergy to topical mometasone furoate confirmed by rechallenge and patch test. Am J Ther 25: e497-e498, 2018.

21. Brănissteanu DE, Pintilie A, Dimitriu A, Cerbu A, Ciobanu D Oanţă A and Tatu AL: Clinical, laboratory and therapeutic profile of lichen planus. Rev Med Chir Soc Med Nat 121: 25-32, 2017.

22. Stojanović-Radić Z, Pejčić M, Dimitrijević M, Aleksić A, Anil Kumar NV, Salehi B, Cho CW, Sharifi-Rad J: Piperine-a major principle of black pepper: A review of its bioactivity and studies. Appl Sci 9: 4270, 2019.

23. Mihăilă B, Dinică RM, Tatu AL and Buzia OD: New insights in vitiligo treatments using bioactive compounds from Piper nigrum. Exp Ther Med 17: 1039-1044, 2019.

24. Tatu AL, Ciobotaru OR, Miulescu M, Buzia OD, Elisei AM, Mardare N, Diaconu C, Robu S and Nwabudike LC: Hydrochlorothiazide: Chemical structure, therapeutic, phototoxic and carcinogenetic effects in dermatology. Rev Chim (Bucharest) 69: 2110-2114, 2018

25. Gerber PA, Buhren BA, Steinhoff M and Homey B: Rosacea: The cytokine and chemokine network. J Investig Dermatol Symp Proc 15: 40-47, 2011.

26. Kim CH, Kim SW and Kim GS: Effects of hydrochlorothiazide and furosemide diuretics on human bone marrow stromal osteoprogenitor cells. Metabolism 49: 17-21, 2000.

27. Yin M, Li G, Song H and Lin S: Identifying the association between interleukin- 6 and lichen planus: A meta-analysis. Biomed Rep 6: 571-575, 2017.

28. Nibali L, Fedele S, D'Aiuto F and Donos N: Interleukin-6 in oral diseases: A review. Oral Dis 18: 236-243, 2012

29. Singh S, Singh U and Pandey SS: Serum concentration of IL-6, IL-2, TNF- $\alpha$, and IFN $\gamma$ in vitiligo patients. Indian J Dermatol 57: 12-14, 2012.

30. Lee HY, Stieger M, Yawalkar N and Kakeda M: Cytokines and chemokines in irritant contact dermatitis. Mediators Inflamm 2013: 916497, 2013

31. Zeng W, Zhang Y, Duan F, Lin T, Liu X, Li D and Wu K Lipopolysaccharide enhances human herpesvirus 1 replication and IL-6 release in epithelial cells. Microb Pathog 140: 103961, 2020.

32. Farsakoglu Y, Palomino-Segura M, Latino I, Zanaga S, Chatziandreou N, Pizzagalli DU, Rinaldi A, Bolis M, Sallusto F, Stein JV and Gonzalez SF: Influenza vaccination induces NK-cell-mediated type-II IFN response that regulates humora immunity in an IL-6-dependent manner. Cell Rep 26: 2307-2315. e5, 2019.

33. Sun X, Tian Q, Wang L, Xue M and Zhong G: IL-6-mediated signaling pathways limit chlamydia muridarum infection and exacerbate its pathogenicity in the mouse genital tract. Microbes Infect 19: 536-545, 2017.

34. Muhsin M, Ajendra J, Gentil K, Berbudi A, Neumann AL, Klaas L, Schmidt KE, Hoerauf A and Hübner MP: IL-6 is required for protective immune responses against early filarial infection. Int J Parasitol 48: 925-935, 2018.

35. Stone SF, Price P, Keane NM, Murray RJ and French MA: Levels of IL- 6 and soluble IL- 6 receptor are increased in HIV patients with a history of immune restoration disease after HAART. HIV Med 3: 21-27, 2002.

36. Modrigan M, Draganescu M, Condratovici CP, Pavel LL and Condratovici AP: Clinical personality patterns in young adults with HIV nosocomial infection from the region of southeast Romania. Mater Plast 54: 175-179, 2017.
37. Tiutiuca C, Drăgănescu M, Iancu AV, Chesaru BI, Arbune M, Maftei N and Popescu E: Resistence profile of the isolated bacterial stems in invasive infections in three hospitals from the south-east of Romania. Rev Chim (Bucharest) 68: 1122-1125, 2017.

38. Saiki P, Nakajima Y, Van Griensven LJLD and Miyazaki K: Real-time monitoring of IL-6 and IL-10 reporter expression for anti-inflammation activity in live RAW 264.7 cells. Biochem Biophys Res Commun 505: 885-890, 2018.

39. Shirakura K, Ishiba R, Kashio T, Sakai M, Fukushima Y, Yamamoto N, Manabe S, Shigesada N, Tanaka T, Hino N, et al: Endothelial Robo4 regulates IL-6 production by endothelial cells and monocytes via a crosstalk mechanism in inflammation. Biochem Biophys Res Commun 495: 801-806, 2018.

40. Uchibori T, Matsuda K, Shimodaira T, Sugano M, Uehara T and Honda T: IL-6 trans-signaling is another pathway to upregulate osteopontin. Cytokine 90: 88-95, 2017.

41. Atzeni F, Nucera V, Masala IF, Sarzi-Puttini P and Bonitta G: Il-6 involvement in pain, fatigue and mood disorders in rheumatoid arthritis and the effects of Il-6 inhibitor sarilumab. Pharmacol Res 149: 104402, 2019.

42. Gao ST, Xu T, Xun CH, Liang WD, Cao R, Mao C and Sheng WB: Significant association of IL-6-572G/C, IL-6-597G/A, and IL-6-174G/C polymorphisms and susceptibility to lumbar degenerative disease: A meta-analysis. Clin Neurol Neurosurg 175 40-46, 2018.

43. Van Gaal LF, Mertens IL and De Block CE: Mechanisms linking obesity with cardiovascular disease. Nature 444: 875-880, 2006.

44. Eder K, Baffy N, Falus A and Fulop AK: The major inflammatory mediator interleukin- 6 and obesity. Inflamm Res 58: 727-736, 2009.

45. Libby P: Inflammation in atherosclerosis. Arterioscler Thromb Vasc Biol 32: 2045-2051, 2012.

46. IL6R Genetics Consortium Emerging Risk Factors Collaboration, Sarwar N, Butterworth AS, Freitag DF, Gregson J, Willeit P, Gorman DN, Gao P, Saleheen D, Rendon A, et al: Interleukin-6 receptor pathways in coronary heart disease: A collaborative meta-analysis of 82 studies. Lancet 379: 1205-1213, 2012.

47. Interleukin-6 Receptor Mendelian Randomisation Analysis (IL6R MR) Consortium, Swerdlow DI, Holmes MV, Kuchenbaecker KB, Engmann JE, Shah T, Sofat R, Guo Y, Chung C, Peasey A, et al: The interleukin-6 receptor as a target for prevention of coronary heart disease: A mendelian randomisation analysis. Lancet 379: 1214-1224, 2012.

48. Fernandez-Real JM, Vayreda M,Richart C, Gutierrez C, Broch M, Vendrell J and Ricart W: Circulating interleukin 6 levels, blood pressure, and insulin sensitivity in apparently healthy men and women. J Clin Endocrinol Metab 86: 1154-1159, 2001.

49. Emerging Risk Factors Collaboration, Kaptoge S, Di Angelantonio E, Lowe G, Pepys MB, Thompson SG, Collins R and Danesh J: C-reactive protein concentration and risk of coronary heart disease, stroke, and mortality: An individual participant meta-analysis. Lancet 375: 132-140, 2010.

50. Hartman J and Frishman WH: Inflammation and atherosclerosis: A review of the role of interleukin-6 in the development of atherosclerosis and the potential for targeted drug therapy. Cardiol Rev 22: 147-151, 2014.

51. Luc G, Bard JM, Juhan-Vague I, Ferrieres J, Evans A, Amouyel P, Arveiler D, Fruchart JC and Ducimetiere P; PRIME Study Group: C-reactive protein, interleukin-6, and fibrinogen as predictors of coronary heart disease: The PRIME study. Arterioscler Thromb Vasc Biol 23: 1255-1261, 2003.

52. Shlipak MG, Ix JH, Bibbins-Domingo K, Lin F and Whooley MA: Biomarkers to predict recurrent cardiovascular disease: The heart and soul study. Am J Med 121: 50-57, 2008.

53. Lee JK, Bettencourt R, Brenner D, Le TA, Barrett-Connor E and Loomba R: Association between serum interleukin- 6 concentrations and mortality in older adults: The Rancho Bernardo study. PLoS One 7: 1-7, 2012.

54. Scharnagl H, Stojakovic T, Weihrauch G, Winkelmann BR, Boehm BO and März W: Interleukin-6 is stronger associated with all-cause and cardiovascular mortality than C-reactive protein, serum amyloid and fibrinogen (the luric study). Atheroscler Suppl 11: 42, 2010.

55. Fan ZX, Hua Q, Li YP, Liu RK and Yang Z: Interleukin-6, but not soluble adhesion molecules, predicts a subsequent mortality from cardiovascular disease in patients with acute ST-segment elevation myocardial infarction. Cell Biochem Biophys 61: 443-448, 2011.

56. Zakynthinos E and Pappa N: Inflammatory biomarkers in coronary artery disease. J Cardiol 53: 317-333, 2009. 
57. Yudkin JS, Kumari M, Humphries SE and Mohamed-Ali V: Inflammation, obesity, stress and coronary heart disease: Is interleukin-6 the link? Atherosclerosis 148: 209-214, 2000.

58. Fontes JA, Rose NR and Čiháková D: The varying faces of IL-6: From cardiac protection to cardiac failure. Cytokine 74: 62-68, 2015.

59. Baune BT, Rothermundt M, Ladwig KH, Meisinger $\mathrm{C}$ and Berger K: Systemic inflammation (interleukin 6) predicts all cause mortality in men: Results from a 9-year follow-up of the MEMO study. Age (Dordr) 33: 209-217, 2011.

60. Fisman EZ, Benderly M, Esper RJ, Behar S, Boyko V, Adler Y, Tanne D, Matas $\mathrm{Z}$ and Tenenbaum A: Interleukin- 6 and the risk of future cardiovascular events in patients with angina pectoris and/or healed myocardial infarction. Am J Cardiol 98: 14-18, 2006.

61. Boekholdt SM and Stroes ES: The interleukin-6 pathway and atherosclerosis. Lancet 379: 1176-1178, 2012.

62. Mendoza CE, Rosado MF and Bernal L: The role of interleukin-6 in cases of cardiac myxoma. Clinical features, immunologic abnormalities, and a possible role in recurrence. Tex Heart Inst J 28: 3-7, 2001

63. Chae CU, Lee RT, Rifai N and Ridker PM: Blood pressure and inflammation in apparently healthy men. Hypertension 38 399-403, 2001

64. Danesh J,Kaptoge S, Mann AG, Sarwar N, Wood A, Angleman SB Wensley F, Higgins JPT, Lennon L, Eiriksdottir G, et al: Long-term interleukin-6 levels and subsequent risk of coronary heart disease: Two new prospective studies and a systematic review. PLoS Med 5: e78, 2008.

65. Volpato S, Guralnik JM, Ferrucci L, Balfour J, Chaves P, Fried LP and Harris TB: Cardiovascular disease, interleukin-6, and risk of mortality in older women: The women's health and aging study. Circulation 103: 947-953, 2001

66. Rao M, Guo D, Perianayagam MC, Tighiouart H, Jaber BL, Pereira BJ and Balakrishnan VS: Plasma interleukin-6 predicts cardiovascular mortality in hemodialysis patients. Am J Kidney Dis 45: 324-333, 2005.

67. Haugen E, Gan LM, Isic A, Skommevik T and Fu M: Increased interleukin- 6 but not tumour necrosis factor-alpha predicts mortality in the population of elderly heart failure patients. Exp Clin Cardiol 13: 19-24, 2008

68. Panichi V, Maggiore U, Taccola D, Migliori M, Rizza GM, Consani C, Bertini A, Sposini S, Perez-Garcia R, Rindi P, et al: Interleukin- 6 is a stronger predictor of total and cardiovascular mortality than C-reactive protein in haemodialysis patients. Nephrol Dial Transplant 19: 1154-1160, 2004.

69. Candore G, Balistreri CR, Listì F, Grimaldi MP, Vasto S Colonna-Romano G, Franceschi C, Lio D, Caselli G and Caruso C: Immunogenetics, gender, and longevity. Ann NY Acad Sci 1089: 516-537, 2006

70. Frangogiannis NG: The inflammatory response in myocardial injury, repair, and remodelling. Nat Rev Cardiol 11: 255-265, 2014.

71. Groot HE, Al Ali L, van der Horst IC, Schurer RA, van der Werf HW, Lipsic E, van Veldhuisen DJ, Karper JC and van der Harst P: Plasma interleukin 6 levels are associated with cardiac function after ST-elevation myocardial infarction. Clin Res Cardiol 108: 612-621, 2019.

72. Empana JP, Jouven X, Canoui-Poitrine F, Luc G, Tafflet M Haas B, Arveiler D, Ferrieres J, Ruidavets JB, Montaye M, et al: C-reactive protein, interleukin 6 , fibrinogen and risk of sudden death in European middle-aged men: The PRIME study. Arterioscler Thromb Vasc Biol 30: 2047-2052, 2010.

73. Samanta A, Cheng G, Davani A, Girgis M, Chen L, Choksi K, Zhao L, Vincent RJ, Hauptman J and Dawn B: Genetic deletion of interleukin-6 attenuates left ventricular dysfunction and remodeling after a reperfused myocardial infarction. Circulation 130 (Suppl 2): A15693, 2014

74. Luna JM, Moon YP, Liu KM, Spitalnik S, Paik MC, Cheung K, Sacco RL and Elkind MS: High-sensitivity C-reactive protein and interleukin-6-dominant inflammation and ischemic stroke risk: The northern Manhattan study. Stroke 45: 979-987, 2014.

75. Bacchiega BC, Bacchiega AB, Usnayo MJ, Bedirian R, Singh G and Pinheiro, GD: Interleukin 6 inhibition and coronary artery disease in a high risk population: A prospective community based clinical study. J Am Heart Assoc 6: e005038, 2017.

76. Tousoulis D, Oikonomou E, Economou EK, Crea F and Kaski JC: Inflammatory cytokines in atherosclerosis: Current therapeutic approaches. Eur Heart J 37: 1723-1732, 2016.
77. Welsh P, Grassia G, Botha S, Sattar N and Maffia P: Targeting inflammation to reduce cardiovascular disease risk: A realistic clinical prospect? Br J Pharmacol 174: 3898-3913, 2017.

78. Jones G, Sebba A, Gu J, Lowenstein MB, Calvo A, Gomez-Reino JJ, Siri DA, Tomsic M, Alecock E, Woodworth T and Genovese MC: Comparison of tocilizumab monotherapy versus methotrexate monotherapy in patients with moderate to severe rheumatoid arthritis: The Ambition study. Ann Rheum Dis 69: 88-96, 2010

79. Smolen JS, Beaulieu A, Rubbert-Roth A, Ramos-Remus C, Rovensky J, Alecock E, Woodworth T and Alten R; OPTION Investigators: Effect of interleukin-6 receptor inhibition with tocilizumab in patients with rheumatoid arthritis (OPTION study): A double-blind, placebo-controlled, randomized trial. Lancet 371: 987-997, 2008.

80. Gabay C, McInnes IB, Kavanaugh A, Tuckwell K, Klearman M, Pulley J and Sattar N: Comparison of lipid and lipid-associated cardiovascular risk marker changes after treatment with tocilizumab or adalimumab in patients with rheumatoid arthritis. Ann Rheum Dis 75: 1806-1812, 2016.

81. Gabay C, Emery P, van Vollenhoven R, Dikranian A, Alten R, Pavelka K, Klearman M, Musselman D, Agarwal S, Green J, et al: Tocilizumab monotherapy versus adalimumab monotherapy for treatment of rheumatoid arthritis (ADACTA): A randomised, double-blind, controlled phase 4 trial. Lancet 381: 1541-1550, 2013.

82. Yokoe I, Kobayashi H, Nishiwaki A, Sugiyama K, Nagasawa Y, Karasawa $\mathrm{H}$, Iwata M, Nozaki T, Ikumi N, Inomata $\mathrm{H}$, et al: FRI0204 effect of tocilizumab treatment on QTc interval in patients with rheumatoid arthritis without cardiac symptoms. Ann Rheum Dis 75 (Suppl 2): S505.1-505, 2016.

83. Kobayashi H, Yokoe I, Nishiwaki A, Sato H and Kobayashi Y: OP0313 effect of tocilizumab on left ventricular function assessed using a comprehensive cardiac magnetic resonance approach in rheumatoid arthritis patients without cardiac symptoms. Ann Rheum Dis 72 (Suppl 3): A160, 2014.

84. Dello SA, Bloemen JG, van de Poll MC, van Dam RM, Stoot JHMB, van den Broek MAJ, Buurman WA, Bemelmans MHA, Olde Damink SWM and Dejong CHC: Gut and liver handling of interleukin-6 during liver resection in man. HPB (Oxford) 13: 324-331, 2011

85. Kornasiewicz O, Grąt M, Dudek K, Lewandowski Z, Gorski Z, Zieniewicz K and Krawczyk M: Serum levels of HGF, IL-6, and TGF- $\alpha$ after benign liver tumor resection. Adv Med Sci 60: 173-177, 2015.

86. Fang C, Cai X, Hayashi S, Hao S, Sakiyama H, Wang X, Yang Q, Akira S, Nishiguchi S, Fujiwara N, et al: Caffeine-stimulated muscle IL-6 mediates alleviation of non-alcoholic fatty liver disease. Biochim Biophys Acta Mol Cell Biol Lipids 1864: 271-280, 2019.

87. Rollwagen FM, Davis TA, Li YY, Pacheco ND and Zhu XL: Orally administered IL-6 induces elevated intestinal GM-CSF gene expression and splenic CFU-GM. Cytokine 27: 107-112, 2004.

88. Grivennikov S, Karin E, Terzic J, Mucida D, Yu GY, Vallabhapurapu S, Scheller J, Rose-John S, Cheroutre H, Eckmann L and Karin M: IL-6 and Stat 3 are required for survival of intestinal epithelial cells and development of colitis-associated cancer. Cancer Cell 15: 103-113, 2009.

89. Waldner MJ and Neurath MF: Master regulator of intestinal disease: IL-6 in chronic inflammation and cancer development. Semin Immunol 26: 75-79, 2014

90. Comen EA, Bowman RL and Kleppe M: Underlying causes and therapeutic targeting of the inflammatory tumor microenvironment. Front Cell Dev Biol 6: 56, 2018.

91. Allen TL, Whitham M and Febbraio MA: IL-6 muscles in on the gut and pancreas to enhance insulin secretion. Cell Metab 15: 8-9, 2012 .

92. Ramis IB, Vianna JS, Gonçalves CV, von Groll A, Dellagostin OA and da Silva PEA: Polymorphisms of the IL-6, IL-8 and IL-10 genes and the risk of gastric pathology in patients infected with Helicobacter pylori. J Microbiol Immunol Infect 50: 153-159, 2017.

93. Lang Lehrskov L, Lyngbaek MP, Soederlund L, Legaard GE, Ehses JA, Heywood SE, Wewer Albrechtsen NJ, Holst JJ, Karstoft K, Pedersen BK and Ellingsgaard H: Interleukin-6 delays gastric emptying in humans with direct effects on glycemic control. Cell Metab 27: 1201-1211.e3, 2018.

94. Fan K, Yang C, Fan Z, Huang Q, Zhang Y, Cheng H, Jin K, Lu Y, Wang Z, Luo G, et al: MUC16 C terminal-induced secretion of tumor-derived IL- 6 contributes to tumor-associated Treg enrichment in pancreatic cancer. Cancer Lett 418: 167-175, 2018. 
95. Hsieh CL, Liu SJ, Shen CR, Chen MY, Hsu SC, Tsai JP, Li YS, Yang CJ, Chong P and Chen HW: IL-6-transfected tumor cells modulate the status of CD8(+) and CD4(+) T cells to control tumor growth. Immunobiology 215: 486-491, 2010.

96.Zhang LJ, Liu W, Gao YM, Qin YJ and Wu RD: The expression of IL-6 and STAT3 might predict progression and unfavorable prognosis in Wilms' tumor. Biochem Biophys Res Commun 435: 408-413, 2013.

97. Wang S, Li L, Zhou Y, He Y, Wei Y and Tao A: Heterotypic cell-in-cell structures in colon cancer can be regulated by IL-6 and lead to tumor immune escape. Exp Cell Res 382: 111447, 2019.

98. Jiang J, Wang GZ, Wang Y, Huang HZ, Li WT and Qu XD: Hypoxia-induced HMGB1 expression of HCC promotes tumor invasiveness and metastasis via regulating macrophage-derived IL-6. Exp Cell Res 367: 81-88, 2018.

99. Fisher DT, Appenheimer MM and Evans SS: The two faces of IL-6 in the tumor microenvironment. Semin Immunol 26: 38-47, 2014.

100.Zhao M: Cytokine storm and immunomodulatory therapy in COVID-19: Role of chloroquine and anti-IL-6 monoclonal antibodies. Int J Antimicrob Agents 55: 105982, 2020.

101. Azzi L, Carcano G, Gianfagna F, Grossi P, Gasperina DD, Genoni A, Fasano M, Sessa F, Tettamanti L, Carinci F, et al Saliva is a reliable tool to detect SARS-CoV-2. J Infect 81: e45-e50, 2020.

102. World Health Organization-Coronavirus disease (COVID-2019) situation reports. Available from: https://www.who. int/docs/default-source/coronaviruse/situation-reports/20200421 -sitrep-92-covid-19.pdf?sfvrsn=38e6b06d_6. Accessed April 23, 2020.

103. Luo P, Liu Y, Qiu L, Liu X, Liu D and Li J: Tocilizumab treatment in COVID-19: A single center experience. J Med Virol 92: 814-818, 2020.

104.Zhang C, Wu Z, Li JW, Zhao $\mathrm{H}$ and Wang GQ: The cytokine release syndrome (CRS) of severe COVID-19 and Interleukin-6 receptor (IL-6R) antagonist Tocilizumab may be the key to reduce the mortality. Int J Antimicrob Agents 55: 105954, 2020

105. Liu B, Li M, Zhou Z, Guan X and Xiang Y: Can we use interleukin-6 (IL-6) blockade for coronavirus disease 2019 (COVID-19)-induced cytokine release syndrome (CRS)? J Autoimmun 111: 102452, 2020
106. Smolen JS, Aletaha D, Choy EH, Jones SA, Takeuchi T and McInnes I: Targeting IL-6: A review of data. Considerations Med 2: 12-18, 2018

107. Valle ML, Dworshak J, Sharma A, Ibrahim AS, Al-Shabrawey M and Sharma S: Inhibition of interleukin-6 trans-signaling prevents inflammation and endothelial barrier disruption in retinal endothelial cells. Exp Eye Res 178: 27-36, 2019.

108. Huizinga TW, Fleischmann RM, Jasson M, Radin AR, van Adelsberg J, Fiore S, Huang X, Yancopoulos GD, Stahl N and Genovese MC: Sarilumab, a fully human monoclonal antibody against IL-6R $\alpha$ in patients with rheumatoid arthritis and an inadequate response to methotrexate: Efficacy and safety results from the randomised SARIL-RA-MOBILITY Part A trial. Ann Rheum Dis 73: 1626-1634, 2014.

109. Tanaka Y and Mola EM: IL-6 targeting compared to TNF targeting in rheumatoid arthritis: Studies of olokizumab, sarilumab and sirukumab. Ann Rheum Dis 73: 1595-1597, 2014.

110. Kretsos K, Golor G, Jullion A, Hickling M, McCabe S, Shaw S, Jose J and Oliver R: Safety and pharmacokinetics of olokizumab, an anti-IL-6 monoclonal antibody, administered to healthy male volunteers: A randomized phase I study. Clin Pharmacol Drug Dev 3: 388-395, 2014.

111. Docea AO, Tsatsakis A, Albulescu D, Cristea O, Zlatian O, Vinceti M, Moschos SA, Tsoukalas D, Goumenou M, Drakoulis N, et al: A new threat from an old enemy: Re-emergence of coronavirus (Review). Int J Mol Med 45: 1631-1643, 2020.

112. Calina D, Docea AO, Petrakis D, Egorov AM, Ishmukhametov AA, Gabibov AG, Shtilman MI, Kostoff R, Carvalho F, Vinceti M, et al: Towards effective COVID-19 vaccines: Updates, perspectives and challenges (Review). Int J Mol Med 46: 3-16, 2020

This work is licensed under a Creative Commons Attribution-NonCommercial-NoDerivatives 4.0 International (CC BY-NC-ND 4.0) License. 